\title{
As estratégias e a organização da indústria de farinha de trigo do Rio Grande do Sul (2001 - 2007) ${ }^{1}$
}

Strategy and organization of the wheat flour industry at Rio Grande do Sul State (2001-2007)

\author{
Pascoal J osé Marion Filho ${ }^{2}$ \\ Vitor Francisco Dalla Corte ${ }^{3}$
}

\begin{abstract}
Resumo: O estudo identifica as estratégias e avalia a organização da indústria de farinha de trigo do Rio Grande do Sul no período de 2001 a 2007. Utiliza-se como base teórica na análise o modelo estrutura-conduta-desempenho (ECD) e as estratégias competitivas de Porter (1980) e de Mintzberg (1988). Os resultados mostram que a concentração da indústria cai de 2001 para 2006 e que existem barreiras à entrada importantes para os ingressantes no setor, como a escala mínima de produção de farinha e a capacidade ociosa das empresas instaladas. Em relação às estratégias competitivas de Porter, a produção com custos mais baixos se destaca. Entre as tipologias de Mintzberg, a qualidade do produto é considerada pelos gestores como sendo o grande diferencial competitivo. A lucratividade das empresas caiu no período analisado, o que caracteriza uma queda no desempenho da indústria.
\end{abstract}

Palavras-chave: estratégias; farinha de trigo; concentração industrial; barreiras à entrada.

\begin{abstract}
The present study identifies the strategies and evaluates the organization of the wheat flour industry the State of Rio Grande do Sul in the period between 2001 and 2007. The theoretical base used in the analysis was the structure-conduct-performance (SCP) model and the competitive strategies by Porter (1980) and Mintzberg (1988). The results demonstrate that industrial concentration declines from 2001 to 2006 and, it exists barriers to entry that are important to the ones who ingress in the sector like flour minimal production scale and the idle capacity of the already installed companies. In relation to Porter's competitive strategies, the production at lower costs is emphasized. Among Mitzemberg's typologies, the product quality is considered by the managers as the major competitive differential. The companies profitability drop in the considered period what characterized a fall in the industry performance.
\end{abstract}

Key Words: strategies; wheat flour; industrial concentration; barriers to entry.

J EL: L16; L21 e L25.

\section{Introdução}

A indústria nacional de farinha de trigo e os demais agentes participantes da cadeia produtiva ainda sofrem os efeitos do fim da regulamentação do governo em 1990 e da queda de barreiras tarifárias e não-tarifárias para a importação de trigo e de farinha de trigo.

Segundo a Associação Brasileira das Indústrias de Trigo - ABITRIGO (2007), em 1988 o país tinha se aproximado da auto-suficiência na produção do trigo, importando 11,3\% das necessidades de consumo do cereal, e depois do fim da regulamentação passou a importar, em média, no período de 1990 a 2006, 65,24\% do consumo brasileiro.

Esta mudança na disponibilidade interna da principal matéria-prima para os produtores de farinha, juntamente com as medidas liberalizantes adotadas pelo

\footnotetext{
${ }^{1}$ Artigo recebido em março de 2010 e aprovado em setembro de 2010.

2 Doutor em Economia Aplicada pela Escola de Agricultura Luiz de Queiroz da Universidade de São Paulo (ESALQ/ USP). Professor Associado do Departamento de Ciências Econômicas da Universidade Federal de Santa Maria (UFSM). E-mail: pascoaljmarion@yahoo.com.br

3 Mestrando em Administração na Universidade Federal de Santa Maria (UFSM). Supervisor de Planejamento Estratégico da Parati S/A. E-mail: vitordallacorte@gmail.com
} 
governo, como a abertura do mercado brasileiro na década 1990 e o fim dos subsídios ao trigo, vem exigindo das empresas uma constante busca por meios de se manterem competitivas num ambiente em permanente mutação. Por isso, a pesquisa objetiva identificar as estratégias e a organização da indústria de farinha de trigo do Rio Grande do Sul no período de 2001 a 2007.

A opção por restringir o estudo ao Rio Grande do Sul deve-se a sua importância na produção nacional de trigo ( $2^{\circ}$ maior produtor) e ao seu pioneirismo e representatividade na produção de farinha de trigo (3o maior produtor).

O artigo está organizado em cinco seções, sendo esta introdução a primeira delas. A segunda seção traz os referenciais teóricos do estudo, o modelo ECD e as estratégias competitivas de Porter e de Mintzberg. Na sequência, faz-se referência à metodologia e a fonte de dados, e, na quarta seção, analisam-se as estratégias e a organização da indústria de farinha de trigo do Rio Grande do Sul. Por fim, na quinta seção, apresentam-se as conclusões da pesquisa.

\section{A Teoria da Organização Industrial e de Estratégias}

Para estudar as estratégias e a organização da indústria de farinha de trigo do Rio Grande do Sul, utilizam-se como referenciais teóricos o modelo ECD (estrutura conduta - desempenho) e as estratégias competitivas de Porter (1980) e de Mintzberg (1988). A seguir, descrevem-se cada um dos referenciais e apresentam-se as fundamentações para as escolhas.

\subsection{O modelo estrutura-conduta-desempenho (ECD)}

O modelo estrutura-conduta-desempenho (ECD) é oriundo da Organização Industrial (OI) e, segundo Farina (1997), serve para determinar as forças responsáveis pela organização da indústria e como estas têm se alterado no tempo. $\mathrm{O}$ modelo visava inicialmente avaliar a relação entre a concentração na indústria e a lucratividade dos oligopólios, objetivando auxiliar na política antitruste dos EUA. Admitia-se que quanto mais concentrado o mercado, maior a possibilidade de ocorrer uma coalizão tácita entre as empresas para maximização conjunta dos lucros, o que resultaria em uma prática semelhante à de um monopólio, trazendo, desta forma, prejuízos para a sociedade.

O relacionamento da estrutura de mercado com o desempenho no modelo, passando pela conduta das empresas e assumindo um sentido de causalidade da primeira para a última, deriva dos modelos de concorrência perfeita e monopólio. De acordo com a teoria econômica neoclássica, a empresa monopolista maximizadora de lucros produz menos e pratica preços mais elevados do que a empresa que atua no mercado de concorrência perfeita, o que é ruim para a sociedade.

Com o passar do tempo, o modelo ECD passou por várias formalizações e, segundo Marion Filho (1997), apesar das versões mais tradicionais considerarem o sentido de causalidade como unidirecional, ou seja, seguindo da estrutura para o desempenho, sendo a primeira determinada exogenamente, as versões mais atualizadas abandonaram este sentido de casualidade, admitindo que a estrutura possa ser determinada endogenamente. Esta visão é compartilhada por Rosa (2001), que se utiliza da citação de Porter (1980) para reforçar a idéia. Segundo Rosa (2001), vários modelos têm explorado aspectos da empresa em um caráter dinâmico, 
considerando que todo o sistema evolui constantemente em função de mudanças internas e externas a ele, o que permite que tais modelos forneçam respostas mais completas e favoráveis em relação aos objetivos pretendidos.

Sobre esta afirmação, Scherer e Ross (1990) afirmam que existem importantes efeitos de feed-back entre as variáveis do modelo. Como exemplo cita que grandes esforços de pesquisa e desenvolvimento (variável da conduta) realizados por uma firma podem alterar a tecnologia predominante na indústria, a estrutura de custos e o grau de diferenciação física do produto. Outro exemplo citado, é que políticas de determinação de preços podem encorajar a entrada de novas firmas no mercado ou expulsar firmas mais fracas, conseqüentemente alterando a estrutura de mercado.

Contudo, adota-se neste artigo o modelo adaptado de Carlton e Perloff (1990) e, a seguir, apresentam-se os seus componentes.

\subsubsection{A estrutura de mercado}

Para Resende e Boff (2002), a estrutura de mercado desempenha um importante papel dentro do modelo ECD. Entretanto, Leite (1998) destaca que o termo tem três sentidos diferentes. O primeiro refere-se às características mais aparentes do mercado, que é definido conforme o número de empresas concorrentes entre si e pela oferta de produtos diferenciados ou homogêneos; o segundo ponto de vista diz respeito ao modelo estrutura-conduta-desempenho, onde as características das firmas estão relacionadas a varáveis como concentração, barreiras à entrada, bens substitutos, dentre outras. Já a terceira maneira de se enfocar estrutura é semelhante ao segundo ponto de vista, contudo, acrescendo-se aspectos que dão um sentido de dinâmica.

Leite (1998) menciona que a estrutura engloba características de organização do mercado e que a mesma influencia estrategicamente a natureza da competição e os preços dentro deste. De acordo com Carlton e Perloff (1990), a estrutura de mercado pode ser definida analisando as seguintes variáveis: número de vendedores/ compradores (concentração), barreiras à entrada, integração vertical, diferenciação do produto e diversificação da produção.

A concentração é um indicador sintético da concorrência existente em um mercado. Para Kon (1994), a medida dá os elementos empíricos necessários para essa avaliação e serve também para comparações intertemporais, o que permite examinar a dinâmica do mercado do lado da oferta.

Farina (1993) lembra que o conceito de concentração não se refere apenas ao número de participantes de um dado mercado; mais do que isto, se refere ao controle de uma grande proporção de uma determinada atividade econômica por uma pequena proporção dos participantes nesta atividade. Sobre a sua quantificação, Kon (1994) afirma que normalmente são utilizados indicadores que seguem três critérios, que são: a capacidade produtiva, o número de empregados e os ativos possuídos. A capacidade produtiva pode estar relacionada à quantidade física de produção ou a valores monetários (valor das vendas, valor adicionado etc.). O número de empregados é normalmente utilizado para mensurar o poder das empresas pela maior facilidade de obter informações. Contudo, esta medida é influenciada pelas técnicas empregadas, pelo grau de integração e pelo nível de automatização das diferentes firmas.

As medidas mais utilizadas para quantificar a concentração em uma indústria, segundo Kon (1994), são a razão de concentração (Cr) e o índice Herfindahl- 
Hirschman (HH). A Razão de concentração (Cr) mede a proporção da indústria de posse das $\mathrm{k}$ maiores empresas, sendo mais utilizado no Brasil as 4 maiores e seus múltiplos $(4,8,16 \ldots)$, tomando-se como base o indicador escolhido. Seu cálculo é dado por:

Sendo:

$$
\mathbf{C r}(\mathrm{k})=\sum_{\mathrm{i}=1}^{\mathrm{k}} \mathbf{P i}
$$

$\mathrm{k}=$ número das maiores empresas que fazem parte do cálculo; e,

$\mathrm{Pi}=$ participação percentual da i-ésima empresa no mercado.

Esta medida é de fácil interpretação e indica à participação no mercado (concentração) das $\mathrm{k}$ maiores empresas que formam a indústria, sendo o máximo 100\% (monopólio).

O Índice de Herfindahl-Hirschman (HH) é definido pela soma dos quadrados da participação percentual de cada empresa em relação ao tamanho total da indústria. Este índice leva em conta todas as empresas da indústria e é calculado pela fórmula apresentada a seguir:

$$
\mathbf{H H}=\sum_{\mathrm{i}=1}^{\mathrm{n}} \mathbf{P i}^{\mathbf{2}}
$$

Sendo:

n: número de empresas da indústria participantes no mercado; e,

Pi: participação percentual da i-ésima empresa no mercado.

Este índice assume o valor máximo de 10.000 (se o Pi estiver em \%), quando existe apenas uma empresa na indústria (monopólio). O índice assume seu menor valor $(10.000 / \mathrm{n})$ quando as empresas têm participação igualitária no mercado. O valor de $\mathrm{HH}$ aumenta conforme aumenta a desigualdade entre as empresas pertencentes à indústria, apresentando-se, desta forma, como um bom indicador da situação de mercado. Convém salientar que o tamanho da empresa é levado em conta pela sua participação (Pi) ao quadrado, ou seja, as empresas menores contribuem menos que proporcionalmente para o valor do índice. Desta forma, quanto maior o índice, mais concentrado é o mercado e, conseqüentemente, menor a concorrência entre as empresas.

Segundo Usdoj (1997), o mercado não é concentrado quando o valor do índice $\mathrm{HH}$ estiver abaixo de 1.000; tem concentração moderada quando se situar no intervalo entre 1.000 e 1.800; e é altamente concentrado quando atingir valor superior a 1.800.

As demais variáveis da estrutura, como barreiras à entrada, integração vertical, diversificação da produção e diferenciação do produto, também são avaliadas para se conhecer a organização da indústria e a sua dinâmica.

As barreiras à entrada, variável da estrutura, são importantes determinantes da conduta e do desempenho da indústria, já que a sua presença, no longo prazo, 
oportuniza a prática de preços acima do nível competitivo (CARLTON e PERLOFF, 1990). Elas também servem de base para a reação de firmas já estabelecidas frente à entrada de novos concorrentes, uma vez que indicam a extensão na qual elas podem elevar seus preços de venda sem induzir a entrada de novos concorrentes na indústria (BEM, 1991).

Segundo Marion Filho (1997), as barreiras à entrada citadas com maior freqüência na literatura econômica são: economias de escala, necessidades de capital, acesso aos canais de distribuição, desvantagens de custos independentes de escala, produto diferenciado e política pública (regulação). Servem como exemplo de barreiras à entrada: o valor do investimento inicial; os acessos à tecnologia e à matéria-prima; a escala mínima de produção para entrar na indústria; a qualificação da mão-de-obra; a ociosidade das empresas instaladas; a dificuldade de colocar o produto no mercado e outras barreiras existentes aqui não especificadas.

A integração vertical pode ser caracterizada como a expansão da indústria além de seu mercado de atuação, podendo esta ser para trás (da indústria para seus fornecedores de matérias-primas e demais insumos) ou para frente (da indústria para os distribuidores). Esta é uma forma de se reduzir custos, assim como proporcionar aos produtores um maior controle sobre o seu ambiente econômico, visto que firmas integradas podem estabelecer uma estrutura de preços verticais, restringindo as margens de lucro dos seus competidores menos integrados (BEM, 1991).

Cabe ainda ressaltar a diversificação da produção e a diferenciação do produto como variáveis estruturais. Segundo Kon (1994), entende-se por diversificação a introdução de um produto em um mercado no qual a firma ainda não participa, ou seja, a busca do investimento em uma nova indústria, modificando sua linha de produção. Já a diferenciação do produto pode ser entendida como a introdução de uma nova mercadoria na gama de produtos de uma empresa para um mercado em específico, que tenha a característica de ser substituta próxima de outra anteriormente por ela produzida. Verifica-se que a definição de diferenciação de Kon (1994) é ampla e que ela pode ser melhor delimitada agregando as visões de Porter e Mintzberg, apresentadas a seguir.

\subsubsection{A conduta das empresas}

O segundo conceito do modelo ECD a ser apresentado é o da conduta. Segundo Bem (1991), ele pode ser expresso como sendo o comportamento que as firmas apresentam no mercado em relação a preços, produção, características do produto, pesquisa e desenvolvimento ( $\mathrm{P} \& D$ ) e propaganda. Além disso, ele é responsável por estabelecer um elo entre a estrutura e o desempenho.

Assim, a conduta consiste nas políticas da empresa em relação ao mercado concorrencial em que a empresa se encontra, seja esta uma política efetiva ou potencial. É avaliando a conduta da empresa que serão demonstradas as políticas de fixação de preços e produção, bem como a fixação de padrões de qualidade e políticas de ação ou coação da empresa (BEM,1991).

Para Leite (1998), a variável conduta é representada pelas estratégias competitivas adotadas pelas empresas quando se relaciona o modelo ECD à competitividade. A conduta de mercado diz respeito aos processos de decisão e as relações intra-industriais, bem como aos padrões de comportamento que as firmas assumem para se ajustar ou se adequar ao mercado no qual elas operam. 
Existem amplas variações de condutas das empresas. No entanto, a maioria dos trabalhos empíricos realizados tem como objetivo determinar a extensão em que os padrões de concorrência ou o comportamento estão associados à estrutura de mercado (determinante da conduta) e ao desempenho de mercado (determinado pela conduta).

No modelo teórico adotado neste trabalho, considera-se como conduta os gastos com pesquisa e desenvolvimento (P\&D), a realização de contratos entre empresas e, de uma forma complementar, as estratégias genéricas de Porter (1980) e Mintzberg (1988), descritas a seguir.

\subsubsection{As estratégias competitivas de Porter}

Os primeiros ensaios acadêmicos sobre estratégia foram produzidos por docentes e discentes da Harvard Business School. Entre os vários estudos acadêmicos desenvolvidos por essa escola, destacam-se os da área de organização industrial (OI), a exemplo do modelo ECD (estrutura, conduta e desempenho) já citado acima.

Porter (1980) define as estratégias competitivas como ações ofensivas ou defensivas para criar uma posição defensável em uma indústria e assim enfrentar as forças competitivas. Genericamente, segundo Porter (1986), pode-se utilizar como formas de competição no mercado a liderança em custo (obter uma vantagem sustentável em termos de custo sobre os demais competidores e utilizá-la como forma de vender produtos a um preço mais baixo), a diferenciação (atender a preferências dos consumidores que não possam ser satisfeitas por um bem padronizado) e o enfoque (ou nicho de mercado, em que os clientes possuem preferências ou exigências únicas).

Porter (1986) também afirma que a empresa que aplica apenas uma das estratégias genéricas apresenta melhor desempenho. As empresas que procuram adotar uma estratégia híbrida ou que fracassam na busca por uma das estratégias foram por ele designadas como stuck-in-the-middle (expressão traduzida para o português como meio-termo). O fato de uma empresa ser classificada como "meiotermo" não significa que ela não emprega métodos e armas competitivas típicas de uma ou mais das estratégias genéricas, mas apenas que a sua estratégia como um todo carece de consistência interna (DESS e DAVIS, 1984 apud SILVA et al., 2003).

Vários estudos sobre estratégia empresarial foram desenvolvidos utilizando as tipologias de Porter (1980), como comprova a revisão de literatura de Miller e Dess (1993), realizada em artigos publicados no J ournal of Management Studies entre 1986 e 1990. Segundo os autores, o trabalho de Porter - Estratégia Competitiva - foi citado, aproximadamente, na metade dos artigos publicados, demonstrando a proliferação e aceitação das idéias do autor.

\subsubsection{Estratégias competitivas de Mintzberg}

Mintzberg (1988) entende que a maioria das estratégias explicitadas na literatura são falhas, pois focam de forma muito estreita alguns tipos especiais ou propoem agregações arbitrárias. Por isso, o autor propôs novas tipologias de estratégias genéricas a partir do conceito de diferenciação, com detalhamento maior do que o apresentado nas estratégias de Porter (1980). 
Segundo Silva et al. (2003), podem-se definir as estratégias genéricas de Mintzberg (1988) como sendo:

- Diferenciação por qualidade - a estratégia se caracteriza pela oferta de um produto melhor do que o dos concorrentes, embora não fundamentalmente diferente (maior confiabilidade, maior durabilidade ou desempenho superior);

- Diferenciação por design (projeto) - ocorre quando se oferece um produto diferente do apresentado pela concorrência. A diferença básica desta estratégia para aquela de diferenciação por qualidade é que a diferenciação por design busca efetivamente oferecer algo diferente e não simplesmente ou necessariamente melhor;

- Diferenciação por suporte - existe quando é oferecido algo mais junto com o produto. Em geral, a ampliação do nível de serviços agregados (prazo de entrega menor, financiamento à venda, assistência técnica etc.) ou a oferta de produtos complementares;

- Diferenciação por imagem - ela se caracteriza pelo desenvolvimento da imagem do produto, tornando-o distinto dos demais. Esta imagem pode ser criada através da propaganda, como também através de técnicas de promoção, apresentação, ou pela inclusão de detalhes que deixam o produto mais atrativo;

- Diferenciação por preço - a estratégia é cobrar um preço mais baixo pelo produto. Se os demais atributos do bem forem iguais ou não muito diferentes dos de seus concorrentes, os consumidores tenderão a preferir aquele que exibir um preço mais baixo. Mintzberg insiste em afirmar que diferenciação por preço não é o mesmo que a minimização de custo de Porter (1980). Isto porque a minimização de custo só se caracteriza como vantagem competitiva caso se traduza em menor preço no mercado (caso fosse visível para o consumidor);

- Não-diferenciação - essa estratégia se baseia no fato de que é possível copiar as ações de outras empresas, desde que o mercado ofereça espaço para produtos concorrentes e a empresa se especialize em acompanhar e imitar os lançamentos dos concorrentes, apoiando seus próprios lançamentos com ações inovadoras e eficientes de marketing. A estratégia de não-diferenciação assemelha-se ao conceito de meio-termo desenvolvido por Porter (1980). Entretanto, duas diferenças merecem destaque em relação ao modelo de Porter:

I. Mintzberg considera que a estratégia pode ser desenvolvida explicitamente, enquanto Porter considera o meio-termo como um tipo residual, resultante da implementação inadequada ou ineficiente de uma das estratégias genéricas puras; e,

II. ao contrário do que Porter supõe para o meio-termo, Mintzberg não condena a estratégia a um desempenho inferior ao das demais estratégias.

Kotha e Vadlamani (1995), em um estudo das empresas de manufatura nos Estados Unidos, concluíram que as tipologias de Mintzberg (1988) têm maior clareza e poder descritivo que as tipologias de Porter (1980). Os autores citam as seguintes possíveis explicações para justificar os resultados: (i) mudanças no ambiente competitivo devido ao incremento da competição global (especialmente no setor de manufatura) e (ii) mudanças decorrentes da utilização de novas tecnologias (por exemplo, just in time). A maior complexidade do novo ambiente competitivo exigiria maior refinamento das tipologias de estratégias genéricas.

Entretanto, estudo realizado por Silva e Melo (1998) no setor de seguros brasileiro confirma o poder descritivo das tipologias de Porter e afirma que as 
mesmas possuem um poder explanatório superior as apresentadas por Minztberg (1988).

Já o trabalho HILL (1988) ressalta que diversos pesquisadores da área de Administração Estratégica têm sugerido a utilização conjunta de estratégias, mesmo ocorrendo superposições de mais de um tipo em uma mesma empresa, sem que isto signifique desempenho inferior.

Neste estudo, utilizam-se as teorias do modelo ECD, de Porter (1980) e de Mintzberg (1988) como complementares, buscando identificar os diferentes posicionamentos das empresas produtoras de farinha de trigo, mesmo que elas não adotem um posicionamento único em relação às estratégias competitivas. A seguir descreve-se o desempenho, último componente do modelo ECD.

\subsubsection{O Desempenho das empresas}

Os resultados obtidos pelas empresas da indústria determinam o desempenho. Segundo Scherer e Ross (1990), o mesmo é conseqüência da conduta ou do comportamento da empresa. Refere-se aos resultados finais atingidos pelas empresas em função da estrutura e da conduta no mercado onde atuam. Com isso, na análise do desempenho industrial, deve-se sempre observar os resultados obtidos (ex-post facto). Para os autores, os trabalhos empíricos concentram-se nos resultados financeiros, sendo a lucratividade uma das variáveis mais utilizadas.

A lucratividade é muitas vezes relacionada ao grau de concentração. Contudo, esta afirmação pode ser difícil de ser comprovada, porque muitas vezes o lucro pode ser resultado de outras fontes, tais como mudanças inesperadas na relação entre a demanda e os custos. Apesar disso, quando os lucros excessivos são mantidos por um longo período de tempo, são persistentes, só podem ser explicados pela existência do poder de mercado.

De acordo com Scherer e Ross (1990), o bom desempenho é multidimensional e engloba os seguintes elementos, não necessariamente nesta ordem de importância:

a) as decisões sobre o que, quanto e como produzir, que devem ser eficientes em dois aspectos: os recursos escassos, que não devem ser desperdiçados, e as decisões de produção, que devem corresponder qualitativa e quantitativamente à demanda dos consumidores;

b) as operações dos produtores devem ser progressivas, tirando vantagem das oportunidades abertas pela ciência para aumentar o output por unidade de input e fornecer aos consumidores novos produtos superiores;

c) as operações dos produtores devem facilitar o emprego total de recursos, em especial os recursos humanos;

d) a distribuição de renda deve ser eqüitativa, o que implica que a remuneração dos produtores não seja excessiva.

Segundo Bem (1991), a evolução dos preços também é uma variável importante do desempenho da indústria, uma vez que a amplitude na mudança reflete as margens de lucro das empresas.

Vê-se que diversas variáveis podem ser utilizadas para avaliar o desempenho. No entanto, utilizam-se neste trabalho as variáveis preço e lucratividade, destacadas na seção da metodologia e coleta de dados. 


\section{Metodologia e Coleta de Dados}

Utiliza-se na análise das estratégias e da organização da indústria de farinha de trigo do Rio Grande do Sul o método descritivo. Segundo Gil (1996), esse tipo de pesquisa têm como objetivo primordial à descrição das características de determinada população ou fenômeno ou, então, o estabelecimento de relações entre variáveis.

Neste trabalho, o intuito é apresentar as modificações do ambiente setorial segundo teorias distintas, mas complementares entre si. Para tanto, utiliza-se o modelo ECD e as estratégias de Porter (1980) e de Mintzberg (1988).

Os dados utilizados na análise são primários e secundários. Os dados primários foram coletados através da aplicação de um questionário estruturado nas empresas produtoras de farinha de trigo do Rio Grande do Sul. Este questionário assemelha-se aos já aplicados por Zaeyen (1986), Moraes (1996) e Marion Filho (1997). Antes do envio, fez-se um pré-teste em duas empresas e alguns ajustes em relação aos termos técnicos utilizados. Em seguida, teve-se o contato telefônico e o envio dos questionários para os gestores das empresas produtoras de farinha de trigo que faziam parte do cadastro industrial da Federação das Indústrias do Rio Grande do Sul (FIERGS) no ano de 2007 (37 empresas). De uma forma complementar a esta relação, foi efetuado um comparativo com as empresas filiadas a ABITRIGO, respectiva associação brasileira destas empresas. Constatou-se que todas as empresas associadas do Rio Grande do Sul na ABITRIGO (06 empresas) constavam no cadastro industrial da FIERGS, fato este que explica a utilização do cadastro da FIERGS (2007) como referência, pois engloba um número maior de empresas.

Apesar dos esforços realizados para obter informações das 37 empresas produtoras de farinha de trigo no Estado, retornaram 11 questionários (29,73\%). No entanto, as empresas respondentes são representativas e juntas utilizavam mais de $67 \%$ do total de empregados efetivos e faturavam mais de 70\% do total da indústria no ano de 2007. Mesmo assim, deve-se lembrar que a amostra é não probabilística.

Os dados secundários foram utilizados para o cálculo do índice de concentração HH (variável da estrutura da indústria) em relação ao total de empregados envolvidos na indústria. Estes dados foram obtidos junto ao Cadastro Industrial da FIERGS para os anos de 2001 e 2006.

\section{As Estratégias e a Organização da Indústria}

Esta seção traz a avaliação da organização, da conduta e do desempenho da indústria de farinha de trigo do Rio Grande do Sul. As estratégias de Porter (1980) e de Mintzberg (1988) complementam a tipificação da conduta.

\subsection{A organização da indústria moageira de trigo do Rio Grande do Sul}

A organização da indústria é feita a partir da concentração na indústria, das barreiras à entrada no setor, da diferenciação do produto, da diversificação da produção e da integração verltical. 


\subsubsection{A concentração na indústria}

A evolução da concentração na indústria de farinha de trigo do Rio Grande do Sul pode ser vista na Tabela 1. Constata-se que o grau de concentração $(\mathrm{Cr})$ na indústria, medido com base nos dados das quatro maiores empresas, em relação ao faturamento e número de empregados, para os anos de 2002, 2004 e 2006, vem declinando. Isso indica que as empresas lideres perderam participação no mercado para as empresas de menor porte.

Tabela 1 - A razão de concentração e o índice de Herfindahl-Hirschman (HH) para a indústria de farinha de trigo do Rio Grande do Sul

\begin{tabular}{c|c|c|c}
\hline \multirow{2}{*}{ Ano } & \multicolumn{2}{|c|}{ Cr4 (\%) } & \multirow{2}{*}{ HH } \\
\cline { 2 - 3 } & Faturamento & № de empregados & \\
\hline 2001 & - & - & 1040,99 \\
2002 & $50,23 \%$ & $48,37 \%$ & - \\
2004 & $41,50 \%$ & $40,32 \%$ & - \\
2006 & $34,46 \%$ & $33,61 \%$ & 526,69 \\
\hline
\end{tabular}

Fonte: Elaborada a partir de dados da pesquisa de campo e dos cadastros industriais da FIERGS de 2002 e 2007.

O índice $\mathrm{HH}$ calculado a partir do número total de empregados nas empresas revela a mesma tendência do Cr4 (ver Tabela 1). Portanto, ele vem corroborar com a afirmação acima de que ocorreu uma queda acentuada na concentração da indústria de 2001 para 2006.

\subsubsection{Barreiras à entrada na indústria de farinha de trigo}

Os resultados da pesquisa de campo mostram que a principal barreira à entrada na indústria de farinha de trigo é o valor do investimento inicial (nota média 8,5). Isto pode ser explicado pela necessidade crescente de capital para se produzir em larga escala, exigência atual do mercado. Além disso, o investimento exigido é altamente especifico, pois exige maquinário diferenciado, que dificilmente pode ser adaptado para a produção de outro bem que não seja farinha de trigo. De qualquer forma, esse tipo de barreira à entrada também é comum em outras indústrias intensivas em capital.

A importância atribuída à quantidade mínima de produção das empresas instaladas é coerente com o valor do investimento inicial (ver Tabela 2), uma vez que a empresa entrante deverá ter economia de escala para competir no mercado. Dados da ABITRIGO (2007) confirmam que o custo de moagem cai à medida que a produção aumenta, pois o custo da tonelada de trigo moída em um moinho com capacidade de 160 toneladas/dia chega a US\$ 62,50 e no de 450 toneladas/ dia cai para US\$ 34,25.

A construção de uma unidade moageira também pode ser considerada uma importante barreira à saída nessa indústria, já que os ativos são específicos. Logo, mesmo diante de uma baixa produtividade dos fatores de produção, enquanto o custo variável for menor do que a receita esperada com a venda de farinha, um pequeno e obsoleto moinho deve continuar em operação, pelo menos até a depreciação física completa de suas instalações (IPEA, 1998). 
Tabela 2 - Principais barreiras à entrada na indústria de farinha de trigo do Rio Grande do Sul em 2007

\begin{tabular}{l|c}
\hline Barreiras à entrada & $\begin{array}{c}\text { Nota média } \\
(0-10)\end{array}$ \\
\hline Valor do investimento inicial & 8,50 \\
Quantidade mínima de produção & 7,50 \\
Capacidade de produção das empresas já instaladas & 7,50 \\
Dificuldade em colocar o produto no mercado & 7,25 \\
Acesso à tecnologia de produção (máquinas) & 6,25 \\
Conhecimento exigido para produzir (fórmulas e processos) & 5,75 \\
Exigência de mão-de-obra especializada & 5,50 \\
Dificuldade na obtenção de matéria-prima & 4,00 \\
\hline
\end{tabular}

Fonte: Elaborada a partir de dados da pesquisa de campo.

Desta forma, moinhos pequenos, incapazes de acompanhar os investimentos necessários para permitir ganhos de escala e ingressar em novos segmentos de mercado, tendem a produzir o mesmo padrão de farinha, continuando na atividade por já terem incorrido em elevados custos irrecuperáveis. Assim, acabam contribuindo para elevar a barreira à entrada no setor moageiro, por demandar altos investimentos iniciais de quem está fora, combinado a exigência de alta capacidade de produção para gerar ganhos de escala.

A mão-de-obra especializada e o conhecimento para produzir (fórmulas e processos), não foram considerados importantes barreiras à entrada, não sendo empecilhos para novas empresas.

Por fim, em relação ao excesso de capacidade de produção das empresas já instaladas e a dificuldade de colocar o produto no mercado, constata-se que elas também se destacam como barreiras à entrada. Estas dificuldades podem ser explicadas pela capacidade ociosa nas empresas atuantes no Estado, que no ano de 2006 era de 49,85\%, segundo dados da ABITRIGO (2007), o que inibe a entrada de novos produtores, e pela rivalidade na indústria causada pela baixa concentração.

\subsubsection{Diferenciação do produto e diversificação na produção de farinha de trigo}

Na indústria do Rio Grande do Sul, a diferenciação do produto ocorre pela produção de farinha de trigo comum (tipo 2), especial (tipo 1) e misturas prontas. As misturas são direcionadas para o uso doméstico, enquanto que as farinhas servem para o uso industrial e doméstico. O que difere os dois tipos de farinha (comum e especial) é a sua qualidade, que depende primordialmente do trigo utilizado no processo de moagem. As misturas prontas agregam outros componentes à farinha de trigo e podem ser utilizadas para produzir pães, bolos, bolachas etc.

Portanto, a produção de farinha de trigo pode ser considerada de baixa diferenciação e o varejo é o seu principal destino (consome, aproximadamente, 2/ 3 das farinhas). As misturas prontas representam uma pequena parcela da produção (2,50\%), o que deixa a concorrência concentrada quase que exclusivamente nas farinhas do tipo 1e 2 (ver Tabela 3).

Verifica-se que o principal destino da farinha de trigo produzida no Rio Grande do Sul é para venda no varejo $(66,62 \%)$, sendo a mais vendida a especial (48,62\%). Para uso industrial, a farinha especial também é a mais vendida (20,38\%). 
Logo, o mercado de farinha de trigo comum é de $28,50 \%$ e o de farinha especial chega a $69,00 \%$ das farinhas.

Tabela 3 - Distribuição da produção de farinha de trigo em 2007

\begin{tabular}{lc}
\hline Distribuição da produção de farinha de trigo & $\%$ \\
\hline Farinha de trigo especial (tipo 1) para o varejo & 48,62 \\
Farinha de trigo especial (tipo 1) para uso industrial & 20,38 \\
Farinha de trigo comum (tipo 2) para o varejo & 18,00 \\
Farinha de trigo comum (tipo 2) para uso industrial & 10,50 \\
Farinha de trigo com misturas prontas (bolos, etc...) & 2,50 \\
\hline
\end{tabular}

Fonte: Dados da pesquisa de campo.

Com relação à diversificação da produção, que é a introdução de um produto em um mercado no qual a empresa ainda não participava, verifica-se que ela é baixa na indústria (2,5\%) e ocorre na elaboração de misturas pré-prontas (utilizadas na produção de bolos, pães integrais etc.).

\subsubsection{Integração vertical na indústria de farinha de trigo}

A integração vertical na indústria pode ser para trás ou para frente (1997). A integração vertical para trás ocorre quando, por exemplo, o produtor de farinha de trigo cultiva o cereal ou atua na distribuição do mesmo. A integração vertical é para frente quando o produtor de farinha de trigo produz massas alimentícias ou qualquer outro produto gerado a partir da mesma.

Os dados da pesquisa de campo evidenciam que a integração é inexpressiva na indústria de farinha de trigo do Rio Grande do Sul. A integração vertical para trás ocorre somente com um dos produtores, que atua na comercialização e armazenagem de trigo. Na integração vertical para frente, uma das empresas produtoras de farinha de trigo também atua na produção de massas alimentícias. Isso não significa que a empresa é mais competitiva ou eficiente, já que o mercado de farinha é bem desenvolvido e concorrencial.

\subsection{A conduta (estratégias competitivas) na indústria}

Segundo o modelo ECD, deve-se esperar que a estrutura da indústria de farinha de trigo influencie a conduta das empresas e seja influenciada pela mesma. Para avaliar as condutas das empresas (estratégias) na indústria de farinha de trigo do Rio Grande do Sul, utiliza-se o modelo ECD e as estratégias competitivas de Porter (1980) e de Mintzberg (1988).

\subsubsection{Gastos em P\&D e contratos nas empresas}

É através de gastos em pesquisa e desenvolvimento (P\&D) que se pode criar e manter formas de concorrência como: redução de preços via redução de custos, qualidade do produto e inovação de produto (desenvolver produtos ainda não disponíveis no mercado). 
Na pesquisa, constatou-se que 25,0\% das empresas investem em P\&D e que os gastos das empresas ficaram em torno de 0,5\% do faturamento. Entretanto, essa atividade limita-se à pesquisa sobre a qualidade do trigo a ser adquirido, uma vez que o estado desse se reflete na produção da farinha.

Na análise dos dados, também chama atenção a fidelidade dos produtores de farinha de trigo aos fornecedores de trigo, uma vez que 75,0\% dos produtores afirmaram que sempre compram trigo dos mesmos fornecedores, visando à manutenção da qualidade. No entanto, verificou-se que 50,0\% dos moageiros utilizam algum tipo de contrato visando ter garantias na transação.

Segundo IPEA (1998), o comportamento na compra de trigo é distinto entre pequenos e grandes produtores. Os moinhos de menor porte têm uma relação continuada e de interesse mútuo com as cooperativas e triticultores, o que não ocorre nos moinhos de grande porte, que necessitam recorrer ao mercado internacional do trigo para melhor desenvolver as suas estratégias de segmentação de mercado, pois há no Brasil uma baixa disponibilidade de trigo de qualidade, como o trigo durum.

\subsubsection{As estratégias competitivas na indústria de farinha de trigo}

Ao utilizar as tipologias de Porter e Mintzberg para identificar as estratégias na indústria, verifica-se que as empresas destacam a qualidade do produto, com nota máxima $(5,00)$ em todos os questionários, e a produção com custo mais baixo (média 3,75). A primeira está relacionada entre as estratégias apresentadas por Mintzberg e a segunda entre as estratégias genéricas de Porter (ver Tabela 4).

Tabela 4 - Notas médias atribuídas às estratégias dos produtores de farinha de trigo em 2007

\begin{tabular}{llc}
\hline \multirow{2}{*}{ Autor } & \multicolumn{1}{c}{ Estratégias adotadas } & $\begin{array}{c}\text { Nota média } \\
(1-5)\end{array}$ \\
\hline \multirow{3}{*}{ Porter } & Produção com o custo mais baixo & 3,75 \\
& Produtos diferenciados & 3,00 \\
& Produção para nichos específicos & 3,00 \\
\hline \multirow{2}{*}{ Mintzberg } & Qualidade do produto & 5,00 \\
& Oferecer algo diferente em relação ao design & 3,00 \\
& Investimentos em propaganda & 2,25 \\
& prazo de pagamento e menor prazo de entrega & 2,00 \\
& Utilizar as mesmas ações das empresas concorrentes & 2,00 \\
& Cobrar um preşo mais baixo indiferente do custo de produção & 1,00 \\
\hline
\end{tabular}

Fonte: Dados da pesquisa de campo.

Ao ressaltar a qualidade como o grande diferencial, todas as empresas afirmaram que investem e adotam algum tipo de sistema de qualidade, mas somente uma empresa da indústria destacou possuir um certificado de qualidade, o ISO 9001:20004.

Estes tipos de estratégias podem estar atrelados às exigências de consumidores que estão buscando produtos com custo mais baixo e produtos que agreguem

4 Para melhor entendimento, ver Mello et al. (2002). 
características diferenciadas como a qualidade. Desta forma, para implementar estratégias de diferenciação, as indústrias de farinha de trigo necessitam de tipos diferentes de trigo, de farinhas específicas e de diferentes qualidades. Logo, os produtores de farinha de trigo para atender essa demanda deveriam aumentar a qualidade, diferenciando os tipos de farinhas produzidas. Atualmente, além das farinhas comum e especial, existem outros tipos de farinhas destinadas especificamente a um produto final.

Esta diferenciação é importante e inicia na triticultura, a partir da necessidade de determinadas matérias-primas. Portanto, existe a possibilidade de expansão da cadeia produtiva a partir da demanda de novos produtos e pela qualidade, ampliando-se as relações intersetoriais, as quais abrem espaço para relações contratuais entre os produtores de trigo, a indústria moageira e as indústrias que utilizam a farinha de trigo como matéria-prima, o que já ocorre no Rio Grande do Sul (ver subitem 4.2.1).

Como a indústria de farinha de trigo do Estado se caracteriza pela formação com empresas de pequeno e médio porte (nenhuma das empresas de produção de farinha de trigo participa da composição das quatro maiores nacionais), entende-se a preocupação estratégica em custos, pois fica difícil a competição com grandes moinhos devido aos ganhos de escala.

A diferenciação por imagem de Mintzberg, que são os gastos com propaganda e promoção dos produtos, não foi considerada relevante pelos produtores da indústria. A diferenciação por preço também não teve destaque, o que mostra que os produtores seguem os preços de mercado e buscam aumentar os ganhos via redução de custos.

\subsection{O desempenho da indústria}

Os indicadores de desempenho avaliados para a indústria de farinha de trigo foram à lucratividade (entende-se por lucratividade o resultado da relação entre o lucro líquido e o faturamento da empresa), a evolução dos preços médios e a produção de farinha de trigo.

Na pesquisa, constatou-se que a lucratividade dos produtores de farinha de trigo caiu, em média, no período analisado. Como a indústria se concentra na produção de farinhas e a produção de misturas é marginal (a qual gera maior valor agregado), a queda na lucratividade pode ser explicada, pelo menos em parte, pela queda dos preços médios da farinha, que passou de $\mathrm{R} \$ 1,20 / \mathrm{kg}$ no ano de 2002 para R\$ 0,92/kg em 2006.

O resultado financeiro das empresas e a queda nos preços médios podem estar relacionados à maior concorrência no mercado interno, uma vez que a produção de farinha no Estado cresceu menos do que a nacional, passou de 872.316 toneladas em 2002 para 918.000 toneladas em 2006 (acréscimo de 5,30\%) e a produção nacional cresceu 16,24\% no mesmo período. Com a menor expansão da indústria gaúcha, caiu a participação de mercado de 12,02\% em 2002 para 10,88\% em 2006. Os índices de concentração reforçam a idéia de aumento da concorrência no mercado, já que houve queda no $\mathrm{Cr} 4$ e no HH (ver subitem 4.1.1).

Portanto, os indicadores de desempenho utilizados para a indústria revelam que está ocorrendo uma perda de competitividade da indústria gaúcha, e ela pode estar associada ao tipo de estratégia mais praticada pelos produtores, o foco na 
qualidade do produto. Acontece que atualmente a qualidade passou a ser considerada apenas como mais um pré-requisito na competição e não mais um diferencial.

Os resultados obtidos também podem ser explicados pela falta de estratégias de diferenciação no mix de produtos ofertados. O volume de produção das indústrias de farinha de trigo de misturas pré-prontas ainda é baixo (representa 2,00\%), quando comparado à produção de farinha de trigo.

\section{Considerações Finais}

O estudo identifica as estratégias e avalia a organização da indústria de farinha de trigo no Rio Grande do Sul. Constatou-se uma queda nos níveis de concentração da indústria com base nos dois índices utilizados, razão de concentração (Cr4) e Herfindahl-Hirschman ( $\mathrm{HH})$. O Cr4, que determina a participação de mercado das quatro maiores empresas em relação ao faturamento, passou de 50,23\% em 2002 para 34,46\% em 2006. O HH, que leva em consideração a totalidade de empresas e foi calculado com base no número de empregados, caiu de 1.040,99 em 2001 para 526,69 em 2006.

A queda na concentração industrial indica que há um aumento da concorrência no setor. Entretanto, foram identificadas algumas barreiras à entrada na indústria que podem limitá-la, como o elevado investimento inicial, que está associado à escala mínima de produção de uma planta competitiva. A economia de escala gerada pela grande produção (redução do custo de moagem) explica a dificuldade porque passam os moinhos do Rio Grande do Sul, pois os produtores são pequenos e médios, o que dificulta a acumulação para permitir ganhos de escala e atingir novos segmentos de mercado.

A conduta das empresas analisadas pode ser justificada pelas características estruturais da indústria. Os gastos em P\&D ainda são baixos (em média, 0,5\% do faturamento) e ocorrem em 27,27\% das empresas. Em relação às estratégias competitivas de Porter (1980) e de Mintzberg (1988), constatou-se que predomina a produção com custos mais baixos de Porter e a qualidade do produto de Mintzberg.

Os esforços estratégicos das empresas, como redução de custos e qualidade do produto, não estão sendo suficientes para melhorar o desempenho da indústria, uma vez que a lucratividade está em queda e os preços da farinha de trigo seguem a mesma tendência. Portanto, os resultados sugerem que as empresas para melhorar a competitividade devem reavaliar as suas condutas e buscar outras estratégias, já que atualmente as praticadas não são mais vistas como de diferenciação dos produtos.

\section{Referências}

ABITRIGO. Associação brasileira das indústrias de trigo. Disponível em: < http:// www.abitrigo.com.br/banco_de_dados.asp>. Acesso em: 30 mai. 2007.

BEM, J . S. Estrutura - conduta - desempenho de mercado das indústrias. Análise, Porto Alegre, v. 1, n. 5, p. 523 - 538, 1991. 
CARLTON B.; PERLOFF, J. Modern industrial organization. Harper Collins, 1990.

FARINA, E. M. M. Q. Competitividade: mercado, estado e organizações. São Paulo: Singular, 1997.

FARINA, E. M. M. Q. Moinho Pacífico: Ajustamentos e Desafios do Livre Mercado. Anais do III Seminário Internacional de Agribusiness. São Paulo: PENSA/ FEA/USP, 1993.

FIERGS. Federação das indústrias do rio grande do sul. Disponível em: http:// www.fiergs.com.br/ cadastroindustrial. Acesso em: 28 jun. 2007.

GIL, A. C. Como elaborar projetos de pesquisa. São Paulo: Atlas, 1996.

HILL, C. Differentiation versus low cost or differentiation and low cost: a contingency framework. The Academy of Management Review, v. 13, n.3, p. 401- 412, Jul. 1988.

IPEA. Instituto de Pesquisa Econômica Aplicada. Competitividade no agribusiness brasileiro. São Paulo, v. II. 1998. 181p.

KON, A. Economia Industrial. São Paulo: Nobel, 1994.

KOTHA, S.; VADLAMANI, B. L. Assessing generic strategies: an empirical investigation of two competing typologies in discrete manufacturing industries. Strategic Management J ournal, v.16, p.75-83, 1995.

LEITE, A. L. Concentração e desempenho competitivo no complexo industrial de papel e celulose 1987-1996. 1998. 99f. Dissertação (Mestrado em Engenharia de Produção) - Universidade Federal de Santa Catarina, Florianópolis, 1998.

MARION FILHO, P. J. A evolução e a organização recente da indústria de móveis nos estados de Santa Catarina e Rio Grande do Sul. 1997. 151f. Tese (Doutorado em Economia Aplicada) - Escola Superior da Agricultura "Luiz de Queiroz" - ESALQ/ USP, Piracicaba, 1997.

MELLO, C. H. P.; SILVA, C. E. S. da; TURRIONI, J. B.; SOUZA, L. G. M. ISO 9001:2000 - Sistema de Gestão da Qualidade para Operações de Produção e Serviços. São Paulo: Atlas, 2002.

MILLER, A.; DESS, G. Assessing Porter's (1980) model in terms of its generalizability, accuracy and simplicity. J ournal of Management Studies, v. 30, n. 4, p.553 585, Jul. 1993.

MINTZBERG, H. Generic Strategies: Toward a Comprehensive Framework, Advances in Strategic Management, v.5J AI Press Greenwich - CT p.1-67, 1988. 
MORAES, M. A. A indústria de madeira preservada no Brasil: um estudo de sua organização industrial. Piracicaba, 1996. 154p. Dissertação de Mestrado - Escola Superior da Agricultura “Luiz de Queiroz" - ESALQ / USP, Piracicaba, 1996.

PORTER, M. E. Competitive strategy: techniques for analysing industries and competitors. NewYork: Free Press, 1980.

PORTER, M. E. Estratégia competitiva. Técnicas para analise de indústrias e concorrência. 7. ed. Rio deJ aneiro: Campus, 1986.

RESENDE, M.; BOFF, H. Concentração industrial. In: KUPFER, D.; HASENCLEVER, L. Economia industrial: fundamentos teóricos e práticas no Brasil. Rio de J aneiro: Campus, 2002.

ROSA, L. C. Contribuição metodológica para análise estrutural de sistemas agroindustriais: um estudo de segmento produtor de vinhos finos do Rio Grande Sul. 2001.Tese (Doutorado em Engenharia de Produção) - Universidade Federal de Santa Catarina, Florianópolis, 2001.

SCHERER, F. M.; ROSS, D. Industrial market structure and economic performance. 3. ed. Chicago: Raud Mc Nally e Co, 1990.

SILVA, J. F.; CARNEIRO, J. M. T.; CAVALCANTI, M. A. D. F. Impactos da privatização sobre as estratégias competitivas de empresas de petróleo: um estudo de caso. RAE-eletrônica, v. 2, n. 2, jul./ dez. 2003.

SILVA, J. F.; MELO, M. A. C. . Tipologias estratégicas concorrentes: um teste empírico na indústria brasileira de seguros. In: 22 ENANPAD, 1998, Foz do Iguaçu. Anais. Rio de J aneiro: ANPAD, 1998.

USDOJ . United States Department of J ustice. The Hirschman - Herfindahl Index, In: Horizontal Merger Guidelines, 1997.

ZAEYEN, A. Estrutura e desempenho do setor de papel e celulose no brasil. 1986. 99f. Dissertação (Mestrado em Economia) - Universidade Federal do Rio de Janeiro, Rio de J aneiro, 1986. 